\title{
Correction of vitamin D status by calcidiol: pharmacokinetic profile, safety, and biochemical effects on bone and mineral metabolism of daily and weekly dosage regimens
}

\author{
S. Minisola ${ }^{1}$ - L. Cianferotti ${ }^{2}$ P. Biondi ${ }^{1} \cdot$ C. Cipriani $^{1}$ - C. Fossi $^{2} \cdot$ F. Franceschelli ${ }^{2}$. \\ F. Giusti ${ }^{2}$ G. Leoncini ${ }^{2}$ - J. Pepe ${ }^{1}$ - H. A. Bischoff-Ferrari ${ }^{3}$ - M. L. Brandi ${ }^{2}$
}

Received: 8 February 2017 / Accepted: 27 July 2017

(C) International Osteoporosis Foundation and National Osteoporosis Foundation 2017

\begin{abstract}
Summary Rationale: Calcidiol can be employed to correct vitamin D deficiency. Main results: Calcidiol administered at daily and weekly regimens over a period of 3 months was able to successfully raise 25-hydroxyvitamin D levels without altering other markers related to bone and mineral metabolism. Significance: Calcidiol supplementation is effective and safe. Introduction The correction of vitamin D status is necessary to maintain an optimal mineral and skeletal homeostasis. Despite cholecalciferol (vitamin $\mathrm{D}_{3}$ ) is the most commonly used drug for vitamin D supplementation, the more hydrophilic compound calcidiol (25-hydroxyvitamin $\mathrm{D}_{3}$ ) can be employed at daily, weekly, and monthly regimens to reach in the short term the target levels of serum 25-hydroxyvitamin D [25(OH)D]. In the administration of different doses of calcidiol pharmacokinetic study (ADDI-D study), the efficacy and safety of daily and weekly dosages of calcidiol were tested.

Methods A total of 87 Caucasian, community-dwelling, postmenopausal women, aged 55 years or older, with vitamin D inadequacy (serum $25(\mathrm{OH}) \mathrm{D}$ levels $<30 \mathrm{ng} / \mathrm{ml}$, with mean 25(OH)D below $20 \mathrm{ng} / \mathrm{ml}$, namely $16.5 \pm 7.5 \mathrm{ng} / \mathrm{ml}$ ) were
\end{abstract}

Electronic supplementary material The online version of this article (doi:10.1007/s00198-017-4180-3) contains supplementary material, which is available to authorized users.

M. L. Brandi

marialuisa.brandi@unifi.it

1 Department of Internal Medicine and Medical Disciplines, "Sapienza", University of Rome, Rome, Italy

2 Metabolic Bone Diseases Unit, Department of Surgery and Translational Medicine, University of Florence, Florence, Italy

3 Department of Geriatrics and Aging Research, University Hospital and University of Zurich, Zürich, Switzerland randomized to receive three different dosages of calcidiol: $20 \mu \mathrm{g} / \mathrm{day}, 40 \mu \mathrm{g} / \mathrm{day}$, and $125 \mu \mathrm{g} / \mathrm{week}$ for 3 months. The attained level of serum 25(OH)D was selected as primary endpoint to assess efficacy, while other parameters of mineral metabolism, (serum calcium, parathyroid hormone, phosphate, FGF23, urinary calcium, and markers of bone turnover) were assessed as secondary endpoints to establish safety.

Results In all the three groups, serum $25(\mathrm{OH}) \mathrm{D}$ values significantly and promptly rose and plateaued above the $30 \mathrm{ng} / \mathrm{ml}$ threshold remaining within safety interval after 14 days of treatment, with similar efficacy for the similar daily and weekly dose regimens. The different dosages were also equally effective in controlling secondary hyperparathyroidism. No significant changes in calcium and phosphate metabolism and in bone turnover markers were observed for any of the treatments, confirming the safety of this compound.

Conclusions The results of this study demonstrate the shortand mid-term efficacy and safety on core parameters of mineral metabolism of different daily or weekly dosages of calcidiol when used to treat vitamin D inadequacy or deficiency in postmenopausal women. Further studies are needed to assess falls as primary outcome of calcidiol supplementation.

Keywords Fracture $\cdot$ Hypovitaminosis D - Osteomalacia . Osteoporosis $\cdot$ Rickets $\cdot$ Vitamin D deficiency

\section{Introduction}

The measurement of serum levels of 25-hydroxyvitamin D [25(OH)D], also referred to as calcidiol or calcifediol, still represents the preferred biomarker for the assessment of vitamin D status, reflecting the endogenous production and the exogenous exposure [1-3]. Calcidiol values are inversely 
correlated with serum PTH. However, owing to several means of calculating the point of maximal suppression of PTH by $25(\mathrm{OH}) \mathrm{D}$, various thresholds (ranging from 12 to $50 \mathrm{ng} / \mathrm{ml}$ ) have been suggested [4-7]. Alternatively, given the diurnal variation of serum PTH and dependency on recent calcium intake and level of mobility [8], a 25(OH)D threshold for bone health was assessed based on optimal hip bone mineral density [1] and reduction of fractures [9] pointing to a threshold of 24 to $30 \mathrm{ng} / \mathrm{ml}$.

An optimal vitamin D status guarantees the maintenance of an appropriate calcium and phosphate homeostasis. Levels of 25(OH)D less than $20 \mathrm{ng} / \mathrm{ml}$ (i.e., $50 \mathrm{nmol} / \mathrm{l}$ ) have been suggested as indicating vitamin D deficiency according to the majority of published guidelines $[1,6]$. Vitamin D deficiency is very common worldwide, especially in seniors and osteoporotic patients, who are at increased risk of fracture. In adults, from a histological point of view, severe vitamin D deficiency $(<10 \mathrm{ng} / \mathrm{ml})$ has been associated with osteomalacia, which, due to impaired mineralization, can hamper bone strength and neutralize or diminish the effectiveness of antiosteoporotic treatments [10]. Accumulated evidences indicate a threshold level range of serum 25(OH)D between 21 and $30 \mathrm{ng} / \mathrm{ml} \mathrm{(53} \mathrm{to} 75 \mathrm{nmol} / \mathrm{l})$ to be recommended in fragile seniors at high risk for falls and fracture [9-11], especially before commencing bone antiresorptive or anabolic therapy [1, 12].

Supplementation with vitamin D inactive precursors of the biologically active vitamin $\mathrm{D}$ metabolite (i.e., $1,25(\mathrm{OH})_{2} \mathrm{D}$ or calcitriol) is an efficient way to correct a poor vitamin D status and restore an optimal mineral homeostasis [1, 13-17].

The most common form of vitamin D supplementation used today is cholecalciferol, also known as native or parental vitamin $\mathrm{D}_{3}$. The recommended daily dosage regimens are usually not able to correct rapidly vitamin D inadequacy. A recent pharmacokinetic study suggested that it takes about 68 days with the daily dose of $800 \mathrm{IU}$ of cholecalciferol to reach the optimal level plateau [15].

Therefore, high bolus doses (also referred to as mega doses) of cholecalciferol have been suggested and employed in order to achieve, in a relatively short time, the target levels of serum $25(\mathrm{OH}) \mathrm{D}$ necessary to begin osteoporosis treatment in subjects at increased risk of fracture [18]. Although the high doses of cholecalciferol (up to 10,000 IU per day) are safe as far as the classic side effects (hypercalciuria and hypercalcemia) are concerned $[19,20]$, unphysiologically high annual doses of vitamin D (300,000 to 500,000 IU) have been associated with an increased risk in falls and fractures [21, 22]. Notably, beyond the major endpoints such as falls and fractures, recent studies also suggested that bolus doses of $100,000 \mathrm{IU}$ vitamin $\mathrm{D}_{3}$ and above might increase bone resorption markers significantly and dose-dependently [23, 24].

Recently, a randomized controlled trial assessed the effect of two higher monthly doses of vitamin D (monthly 60,000 IU and $24,000 \mathrm{IU}+300 \mu \mathrm{g}$ of calcidiol) in lowering the risk of functional decline and falls in community-dwelling men and women aged 70 or older with a prior fall event and compared with a monthly standard dose of 24,000 IU vitamin D (equivalent to 800 IU per day). Contrary to the expectations of the authors, the higher monthly bolus doses did not improve lower extremity function superior to the standard monthly dose and increase the odds of falling significantly despite raising 25(OH) levels more effectively [11]. These results have been confirmed by a study carried out in a population of vitamin D deficient elderly women (serum 25(OH)D less than $20 \mathrm{ng} / \mathrm{ml}$ ) randomized to receive daily supplements of cholecalciferol at different dosages, with falls as primary outcome. In this group, while medium doses of vitamin D (i.e., daily dosages of 1600 , 2400 , and $3200 \mathrm{IU}$ ) were proven to prevent falls with respect to ineffective low doses (i.e., daily dosages of 400 and $800 \mathrm{IU}$ ), greater doses (i.e., daily dosages of 4000 and $4800 \mathrm{IU})$ leading to higher serum $25(\mathrm{OH}) \mathrm{D}$ concentrations $(>40-45 \mathrm{ng} / \mathrm{ml})$ increased fall rate [25].

Based on these data and the trials outlined earlier on the high annual doses, bolus applications of vitamin D administered intermittently are not warranted in seniors at increased risk of falling. Although no definitive conclusions can be drawn so far on this finding and no causal relationship has been demonstrated, it is nowadays not advisable to administer large doses of cholecalciferol at large intervals of time, according to most guidelines $[1,12]$. Notably, higher daily doses of vitamin $\mathrm{D}$ need further exploration.

Calcidiol, the direct precursor of calcitriol, can represent an alternative strategy to enhance circulating serum $25(\mathrm{OH}) \mathrm{D}$ levels [15-17, 26, 27]. Several pharmacokinetic studies performed in the last four decades have demonstrated its hydrophilic properties, leading to higher solubility in organic solvents, lower trapping in the adipose tissues, smaller distribution volume, and shorter half-life (10-13 days), when compared to the parental compound cholecalciferol (30-45 days) [13, 26, $28]$. The good predictability of achieved $25(\mathrm{OH}) \mathrm{D}$ levels in the short term, along with the effective PTH suppression and manageability in case of intoxication, may confirm the advantages of calcidiol supplementation versus cholecalciferol [14, 16]. Moreover, greater affinity of calcidiol for vitamin D binding protein (VDBP) allows a more efficient internalization in cells expressing the megalin-cubilin system of endocytic receptors, such as the parathyroids and the renal tissue [29].

The administration of calcidiol may be preferable in several conditions [13]. An example is offered by the alteration of liver cytochrome enzymes required for 25 hydroxylation $[14,30]$. In the case of intestinal malabsorption, especially when associated with and steatorrhoea, calcidiol is better absorbed than cholecalciferol [31]. In addition, since a PTH-mediated inhibition of liver cytochrome isoforms has been shown in uremia, calcidiol utilization, instead of cholecalciferol, has been proposed for patients with chronic kidney disease [32]. 
The pharmacokinetics of calcidiol and cholecalciferol has been recently compared in a randomized, controlled parallelgroup study [15]. Calcidiol administered daily, weekly, or in single bolus has been shown to be more effective and rapid in rising serum $25(\mathrm{OH}) \mathrm{D}$ levels with respect to cholecalciferol given at comparable doses daily (20 $\mathrm{gg} /$ day), weekly $(140 \mu \mathrm{g} /$ week for 15 weeks), or in single bolus $(140 \mu \mathrm{g})$, with no risk of vitamin D intoxication [15]. Notably, the authors assessed also several clinical endpoints providing evidence that calcidiol given daily or weekly may be more effective in maintaining or improving lower extremity function and lowering systolic blood pressure among young postmenopausal women [16].

Calcidiol diluted in propylene glycol at a concentration of $150 \mu \mathrm{g} / \mathrm{ml}$ (5 $\mu \mathrm{g}$ calcidiol/drop) and administered as oral drops is registered and included in the European Pharmacopeia for the treatment of rickets due to vitamin D deficiency in children, as well as for vitamin D deficiency, osteomalacia, and spasmophilia in adults, plus additional indications in the various EU Countries [13].

The aim of this study has been to further analyze and describe the therapeutic regimens of calcidiol in terms of intervals of administration, and the mid-term effects on mineral and bone metabolism.

\section{Methods}

The administration of different doses of calcidiol study (ADDI-D study, EudraCT number: 2013-002648-10) is a multicenter, randomized, open label, three-arm, parallel group, and comparative phase III study. The study drug was calcidiol (Didrogyl®, solution, containing $1.5 \mathrm{mg}$ of calcidiol and $10 \mathrm{ml}$ propylene glycol in a dropper bottle, one drop $=5 \mu \mathrm{g}$ calcidiol), to be taken in the morning in fasting state.

The primary objective of the study was to compare the effects of three different therapeutic regimens of calcidiol on the increase of circulating levels of serum 25(OH)D. Secondary objectives were to compare the effects of three different therapeutic regimens of calcidiol on changes of serum and urinary levels of mineral and bone biomarkers as compared at baseline.

The primary efficacy endpoint (primary variable) was represented by the attained circulating values of $25(\mathrm{OH}) \mathrm{D}$ at 3 months of treatment. Secondary efficacy endpoints (secondary variables) were the measurement of serum bone alkaline phosphatase (BALP), parathyroid hormone (PTH), $1,25(\mathrm{OH})_{2} \mathrm{D}, \mathrm{VDBP}$, and 24-h urine calcium over 3 months of treatment. Secondary safety endpoints were incidence of adverse events (AEs), serum calcium (corrected), ionized calcium, phosphate, creatinine, C-terminal telopeptides of type I collagen (CTX), fibroblast growth factor 23 (FGF 23), 24-h urinary calcium, and urinary deoxypiridinoline (DPD).
The study group was composed of Caucasian, communitydwelling, postmenopausal women, aged 55 years or older (years since menopause $>2$ ) with vitamin D inadequacy [i.e., serum $25(\mathrm{OH})$ D levels less than $30 \mathrm{ng} / \mathrm{ml}$ or $75 \mathrm{mmol} / \mathrm{l}]$, adequate calcium intake (1000 mg/day), and BMI $<30$, consecutively recruited in two Italian referral centers for osteoporosis and metabolic bone diseases at the University Hospital of Florence, Florence, and University Hospital of Rome, Umberto I, respectively. The local internal review board of the two institutions approved the study. An informed consent was obtained from each participant.

Potentially eligible women were subjected to an assessment visit, consisting of medical history, clinical (vitals, weight, height, physical examination including blood pressure and pulse rate), and biochemical evaluations. An estimate of calcium intake was performed by administering a specific nutritional questionnaire [33].

Subjects were excluded on the basis of general criteria, as well as specific medical and therapeutic conditions (progressive major illness, severe malabsoption syndrome, IV stage chronic kidney disease, Paget's disease of bone, primary hyperparathyroidism/hypoparathyroidism, hypercalcemia, sarcoidosis, hypercalciuria, intolerance to calcidiol, treatments interfering with bone and mineral metabolism such as glucocorticoids, diuretics, lithium, immunosuppressants, antiretroviral therapy, and other drugs interfering with vitamin $\mathrm{D}$ absorption and catabolism). In particular, it was necessary for the candidates not to be exposed either to cholecalciferol ( $>400$ IU/day in the previous month, doses $>10,000$ IU within the previous 3 months, or doses $>50,000$ IU within the previous 12 months) or to calcidiol and active vitamin D analogs during the 6 months prior to selection.

After the assessment visit, eligible subjects were randomized through a computer-based randomization system into three groups: group 1, receiving oral calcidiol $20 \mu \mathrm{g}$ (Didrogyl@ 4 drops) daily; group 2, receiving calcidiol $40 \mu \mathrm{g}$ (Didrogyl@ 8 drops) daily; and group 3, receiving $125 \mu \mathrm{g}$ (Didrogyl@ 25 drops) weekly. Thus, group 3 received on a weekly basis a similar dose as compared to group 1, taking calcidiol over 7 days. The $20 \mu \mathrm{g}$ dosage was chosen because of the equivalence (in $\mu \mathrm{g}$ ) to $800 \mathrm{IU}$ of cholecalciferol, which is still considered the standard daily dose of vitamin $\mathrm{D}_{3}$ [15-17]. It was decided not to exceed $125 \mu \mathrm{g}$ for safety reason and possible side effects, since previous studies [15] showed that the administration of $140 \mu \mathrm{g} /$ week in a single dose, although safe in terms of hypercalciuria and hypercalcemia, was followed by peaks in serum concentration of $25(\mathrm{OH}) \mathrm{D}$ nearly approaching $50 \mathrm{ng} / \mathrm{ml}$ possibly linked to non-classical side effects such as falls or increase in bone turnover markers $[15,23,24]$. Patients were evaluated at baseline, and 7, 14, 21, 28, 60, and 90 days, afterwards. Adverse events, compliance, and concomitant treatments were recorded at each time point. 
Serum 25(OH)D, VDBP, calcium, phosphate, albumin, ionized calcium, creatinine, bone alkaline phosphatase, and CTX were assayed at each visit. Serum PTH, $1,25(\mathrm{OH})_{2} \mathrm{D}$, intact FGF23, alkaline phosphatase (AP), albumin, total proteins, bilirubin, ASAT, ALAT, GGT, Na, $\mathrm{Cl}$, and $\mathrm{K}$ were assessed at baseline and at 90 days. Urinary parameters such as 24-h urinary calcium, phosphate, and creatinine and DPD were assessed at each time point. Albumin and total proteins were determined for the calculation of corrected serum calcium, while AP, bilirubin, ASAT, ALAT, GGT, Na, Cl, K, urinary phosphate, and creatinine were assessed for safety issues. These latter parameters were not included in the endpoints of the study.

The determinations of serum 25(OH)D (vitamin D TOTAL Assay, DiaSorin USA, Stillwater, MN, USA, competitive onestep backfill chemiluminescence assay, with a measurement range of $4-150 \mathrm{ng} / \mathrm{ml}$ and functional sensitivity of $4.0 \mathrm{ng} / \mathrm{ml}$ or less; intra- and inter-assay precision of 8.9 and $12.8 \%$, respectively, with reported cross-reactivity values of $100 \%$ for both 25-hydroxyvitamin D2 and 25-hydroxyvitamin D3), intact FGF23 (ELISA, Immutopics, Inc., CA, USA; CV intra-assay $4.5 \%$, CV inter-assay $11.5 \%$ ), and VDBP (ELISA, DRG Instruments $\mathrm{GmbH}$, Germany; CV intra-assay $5.5 \%$, CV inter-assay: $12.5 \%$ ) were performed on frozen samples and centralized at the University Hospital of Rome [for serum 25(OH)D samples, in a laboratory (no. 140) accredited to Vitamin D Eternal Quality Assessment Scheme, DEQAS] and University Hospital of Florence (for serum intact FGF23 and VDBP samples). The measurements of BALP (immunoassay, IDS-iSYS Multi-Discipline Automated System, UK), CTX (electrochemiluminescent assay, Cobas 601, Roche Diagnostics Gmb, Germany), DPD (chemiluminescent assay, Immulite, 2000, Siemens, UK), PTH (electrochemiluminescent assay, Cobas 601, Roche Diagnostics Gmb, Germany), and $1,25(\mathrm{OH})_{2} \mathrm{D}$ (chemiluminescent assay, IDS-iSYS, Belgium) were carried out in central routine laboratory on frozen samples at University Hospital of Florence. All the other measurements, including ionized calcium, were carried out at local recruiting centers; random samples were assayed in a central laboratory for quality assurance.

All subjects were advised to maintain a systematic daily calcium intake of $1000 \mathrm{mg}$ /day from dietary sources. When this was not achieved by diet only, calcium supplements $(500 \mathrm{mg} /$ day, to be taken at lunchtime) were also administered.

Based on the intention-to-treat principle, the full analysis set (FAS) corresponds to patients who have taken at least one dose of study treatment after randomization. The safety population consisted of all patients who received any study medication and was based on the treatment they actually received.

For the primary variable [serum $25(\mathrm{OH}) \mathrm{D}$ ], the absolute change at the final visit in respect to baseline $25(\mathrm{OH}) \mathrm{D}$ has been estimated in the FAS population using analysis of variance (ANOVA). The model has included fixed effect terms for treatment. Considering that the central laboratory evaluated all main biochemical data and no evidence for center effect has been evidenced in preliminary analyses, final analyses do not take into account the center effect. Multiple comparison tests for main level effects in the model have been carried out using post hoc Bonferroni test. Sensitivity analyses on primary variable has been conducted applying analysis of co-variance (ANCOVA) on time profile using baseline data as co-variate in order, analysis of co-variance (ANCOVA) on time profile above the treatment response using baseline data as co-variate, dosage treatment, visit, and dose-visit interaction. Student $t$ test has been used to evaluate intra-treatment change from baseline.

As far as secondary variables are concerned, the treatment effect has been estimated in the FAS population, and only biochemical relevant parameters have been processed with ANOVA for repeated measures. The model included dosage effect, visit, and dosage-visit interaction.

Safety analyses have been carried out on the safety population. Laboratory parameters have been described using the appropriate summary statistics at each visit stratified by treatment. A potentially clinically significant abnormal value has been evidenced.

Vital signs have been described by group of treatment. A potentially clinically significant abnormal value has been evidenced.

A sample size of 72 subjects was calculated to demonstrate a between-factor effect (Cohen's $d$ ) of 0.45 in an ANOVA repeated measure analysis, considering alpha and beta levels of 0.05 , and the contrast between basic and final visit as primary end point. In order to be more conservative and taking into account around $15 \%$ of drop-outs during the study, the final sample size estimation was 84 subjects ( 28 in each group).

\section{Results}

A total of 87 women with vitamin D inadequacy were randomized to receive three different dosages of calcidiol. Three patients did not assume any treatment and then were therefore excluded from further analyses. Twenty-seven patients received calcidiol at the dosage of $20 \mu \mathrm{g}$ (4 drops)/day (dosage 1), 28 patients received calcidiol at the dosage of $40 \mu \mathrm{g}$ (8 drops)/day (dosage 2), and 29 patients received calcidiol at the dosage of $125 \mu \mathrm{g}$ ( 25 drops) weekly (dosage 3 ).

The treatment groups were comparable for baseline demographic and clinical characteristics (age, age of menarche, age of menopause, height, weight, BMI, and body surface area), and calcium intake (including calcium as daily supplement for patients not reaching $1000 \mathrm{mg}$ /day, as specified above), with no observed statistically significant difference for the different parameters (Table 1). Regarding vitamin D status, almost two thirds $(62.1 \%)$ of the women showed levels of serum 25(OH)D less than $20 \mathrm{ng} / \mathrm{ml}$, with a mean serum 25(OH)D 
Table 1 Baseline characteristics of women in the three randomization groups

\begin{tabular}{|c|c|c|c|}
\hline & Treatment group of calcidiol & $n$ & Mean \pm SD \\
\hline \multirow[t]{3}{*}{ Age (years) } & $20 \mu \mathrm{g} /$ day & 27 & $69.9 \pm 8.0$ \\
\hline & $40 \mu \mathrm{g} /$ day & 28 & $64.4 \pm 6.8$ \\
\hline & $125 \mu \mathrm{g} /$ week & 29 & $66.2 \pm 7.8$ \\
\hline \multirow[t]{3}{*}{ Age of menarche } & $20 \mu \mathrm{g} /$ day & 27 & $12.6 \pm 1.6$ \\
\hline & $40 \mu \mathrm{g} /$ day & 28 & $12.4 \pm 1.5$ \\
\hline & $125 \mu \mathrm{g} /$ week & 29 & $13.1 \pm 1.7$ \\
\hline \multirow[t]{3}{*}{ Age of menopause } & $20 \mu \mathrm{g} /$ day & 27 & $47.6 \pm 5.8$ \\
\hline & $40 \mu \mathrm{g} /$ day & 28 & $49.3 \pm 5.6$ \\
\hline & $125 \mu \mathrm{g} /$ week & 29 & $49.0 \pm 5.3$ \\
\hline \multirow[t]{3}{*}{ Height (m) } & $20 \mu \mathrm{g} /$ day & 27 & $160.0 \pm 7.4$ \\
\hline & $40 \mu \mathrm{g} /$ day & 28 & $160.9 \pm 6.7$ \\
\hline & $125 \mu \mathrm{g} /$ week & 29 & $158.7 \pm 6.3$ \\
\hline \multirow[t]{3}{*}{ Weight $(\mathrm{Kg})$} & $20 \mu \mathrm{g} /$ day & 27 & $63.9 \pm 7.3$ \\
\hline & $40 \mu \mathrm{g} /$ day & 28 & $64.0 \pm 8.6$ \\
\hline & $125 \mu \mathrm{g} /$ week & 29 & $62.9 \pm 9.9$ \\
\hline \multirow[t]{3}{*}{ BMI $\left(\mathrm{Kg} / \mathrm{m}^{2}\right)$} & $20 \mu \mathrm{g} /$ day & 27 & $25.0 \pm 3.0$ \\
\hline & $40 \mu \mathrm{g} / \mathrm{day}$ & 28 & $24.7 \pm 2.6$ \\
\hline & $125 \mu \mathrm{g} /$ week & 29 & $25.0 \pm 3.8$ \\
\hline \multirow[t]{3}{*}{$\operatorname{BSA}\left(\mathrm{m}^{2}\right)$} & $20 \mu \mathrm{g} / \mathrm{day}$ & 27 & $1.7 \pm 0.1$ \\
\hline & $40 \mu \mathrm{g} /$ day & 28 & $1.7 \pm 0.1$ \\
\hline & $125 \mu \mathrm{g} /$ week & 29 & $1.7 \pm 0.1$ \\
\hline \multirow{3}{*}{$\begin{array}{l}\text { Calcium intake } \\
(\mathrm{mg} / \text { day) }\end{array}$} & $20 \mu \mathrm{g} / \mathrm{day}$ & 27 & $1035.7 \pm 323.6$ \\
\hline & $40 \mu \mathrm{g} /$ day & 28 & $912.8 \pm 386.4$ \\
\hline & $125 \mu \mathrm{g} /$ week & 29 & $964.6 \pm 426.7$ \\
\hline
\end{tabular}

$n$ number of subjects, $B M I$ body mass index, $B S A$ body surface area

levels of $16.5 \pm 7.5 \mathrm{ng} / \mathrm{ml}$ and no significant difference between the treatment groups. Mean levels of serum 25(OH)D were comparable and below $20 \mathrm{ng} / \mathrm{ml}$, namely $15.1 \pm 7.4 \mathrm{ng} /$ $\mathrm{ml}$ in group 1, $16.8 \pm 6.6 \mathrm{ng} / \mathrm{ml}$ in group 2, and $16.4 \pm 9.7 \mathrm{ng} /$ $\mathrm{ml}$ in group 3 (Supplementary Table 1).

No alterations in vital signs or clinical abnormalities were recorded at the screening visit nor in the following examinations.

In Fig. 1, the profiles of serum 25(OH)D concentration attained with the three dose regimens of calcidiol are displayed. The ANOVA on absolute change of 25(OH)D levels from baseline (primary analysis) showed statistical difference between the final attained $25(\mathrm{OH})$ concentration at the end of the study period versus baseline levels in each of the three groups $(p<0.0001)$. Difference at day 90 in respect to baseline has been confirmed by paired Student $t$ test for all treatment groups $(p<0.0001)$. Post hoc Bonferroni multiple comparison evidenced statistical difference between dosage 1 and 2 (estimated difference -23.44 with SE estimated 5.30 associated to probability corrected level equal to $<0.0001$ ) and dosage 2 and 3 (estimated difference 28.46 with SE estimated 5.20 associated to probability corrected level equal to $<0.0001$ ); no statistical difference has detected between dosage 1 and 3 (estimated difference 5.02 with SE estimated 5.30 associated to probability corrected level equal to 1.0000 ). Sensitivity analyses have confirmed results of the primary analysis. Analysis on time profile has evidenced a statistical significant difference in treatments response during time at the various time points for each treatment group (ANOVA for repeated measures: $p<0.0001$ for each value versus respective baseline).

Thus, all dosage schemes enabled a significant increase in serum 25(OH)D levels at the end of treatment period with restrained variability, as demonstrated by $95 \%$ confidence limits. Considering two populations of women, those with baseline serum 25(OH)D levels below $20 \mathrm{ng} / \mathrm{ml}$ and those with serum $25(\mathrm{OH}) \mathrm{D}$ levels between 20 and $30 \mathrm{ng} / \mathrm{ml}$, no differences were observed in terms of absolute percentual increase in serum $25(\mathrm{OH}) \mathrm{D}$ levels (final versus baseline) between the two categories of patients for each treatment group $(+168.2$ and $+203.6 \%$ in group $1,+297.0$ and $299.3 \%$ in group 2, 161.6 and $152.5 \%$ in group 3, respectively).

After 14 days of treatment, the majority (75\%) of patients reached lower limit for serum $25(\mathrm{OH}) \mathrm{D}$ sufficiency (i.e., $20 \mathrm{ng} / \mathrm{ml}$ ); then, a further increase was observed, maintaining the serum concentration in the classical safety window (30$100 \mathrm{ng} / \mathrm{ml})$. While 25(OH)D levels were similar for the groups receiving $20 \mu \mathrm{g} /$ day or $125 \mu \mathrm{g} /$ week at each time point, with a final attained 25(OH)D of $49.3 \pm 19.5$ and $46.4 \pm 15 \mathrm{ng} / \mathrm{ml}$, respectively, they almost doubled in the group supplemented with $40 \mu \mathrm{g} /$ day, reaching a mean $25(\mathrm{OH}) \mathrm{D}$ of $74.8 \pm 22.5 \mathrm{ng} /$ $\mathrm{ml}$. Moreover, no difference was observed in serum 25(OH)D concentrations between 30 and 90 days of treatment, indicating a plateau phase during calcidiol administration in the short-tomedium term.

Figures 2, 3, 4, to 5 show the time course of different serum and urinary biochemical and hormonal markers (reported in detail in Supplementary Tables 1 and 2). Serum total and ionized calcium remained within the normal range for the duration of the study in the three groups of patients. As demonstrated by ANOVA for repeated measures, no statistical differences between the three treatment groups and versus baseline were observed for serum total calcium and ionized calcium, despite a statistical difference was shown for ionized calcium for visit term ( $F$ value $=5.99$, Prob $>F<0.0001$ ), which should be interpreted as consequence due to the relevant fluctuation of values at day 21 (Supplementary Table 1, Fig. 2a, b).

Serum phosphate, creatinine, and markers of bone turnover (BALP and CTX) stayed within the normal range in the three groups. No peak concentrations in bone turnover markers were observed. ANOVA for repeated measures confirmed no differences between treatments, despite significant fluctuation during the visits for serum phosphate $(F$ value $=2.27$, Prob $>F=0.0451)$, serum creatinine $(F$ value $=1.27$, Prob $>F=0.2825$ ) and markers of bone turnover such as 
Fig. 1 Time profile of the response of serum $25(\mathrm{OH}) \mathrm{D}(\mathrm{ng} /$ $\mathrm{ml}$ ) to different dose regimens of calcidiol at various time points (mean $\pm \mathrm{SE})$; the dotted lines indicate serum levels of $25(\mathrm{OH}) \mathrm{D}$ vitamin D sufficiency/adequacy by different guidelines (i.e., 20 and $30 \mathrm{ng} / \mathrm{ml})(* p<0.05$ and $* * p<0.001$ versus baseline for all treatment groups)

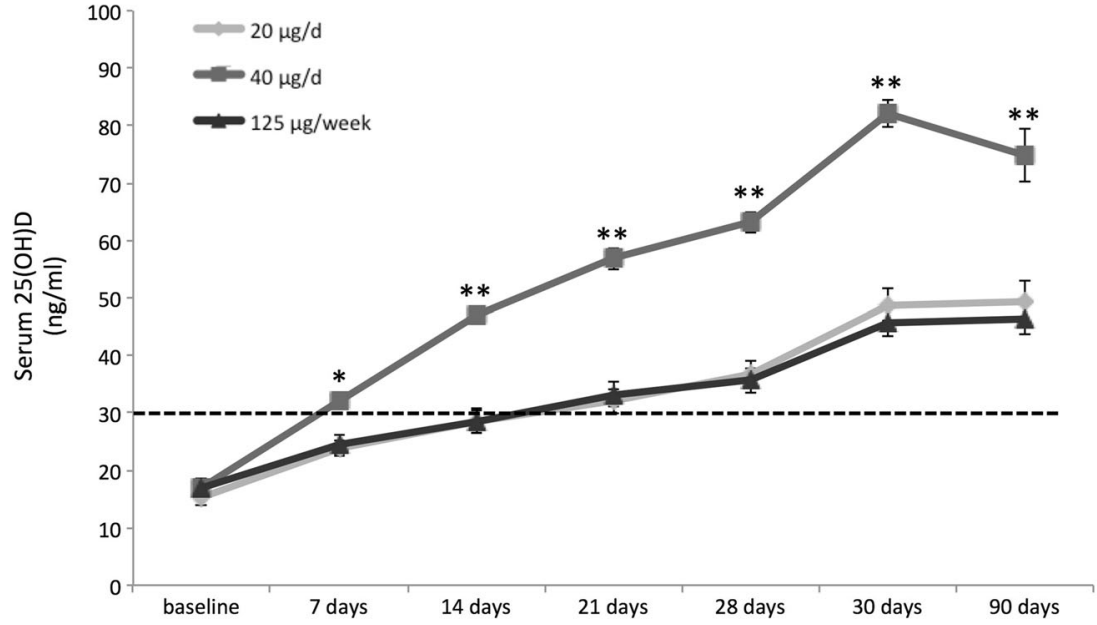

BALP $(F$ value $=5.00$, Prob $>F=0.0002)$ and CTX $(F$ value $=2.91$, Prob $>F=0.0128)$ (Supplementary Table 1 , Fig. 2c, d, Fig. 3a, b).

Hormonal parameters were determined at baseline and final evaluation (Supplementary Table 2). Serum levels of PTH, $1,25(\mathrm{OH})_{2} \mathrm{D}$ and intact FGF23 did not vary among the different treatments (ANOVA). While 1,25(OH)2D and intact FGF23 levels remained stable during calcidiol supplementation in the three groups of treatment (final versus baseline serum $1,25(\mathrm{OH})_{2} \mathrm{D}: p=0.44, p=0.46$, and $p=0.99$ for dosage 1, 2, and 3, respectively; final versus baseline serum FGF23:
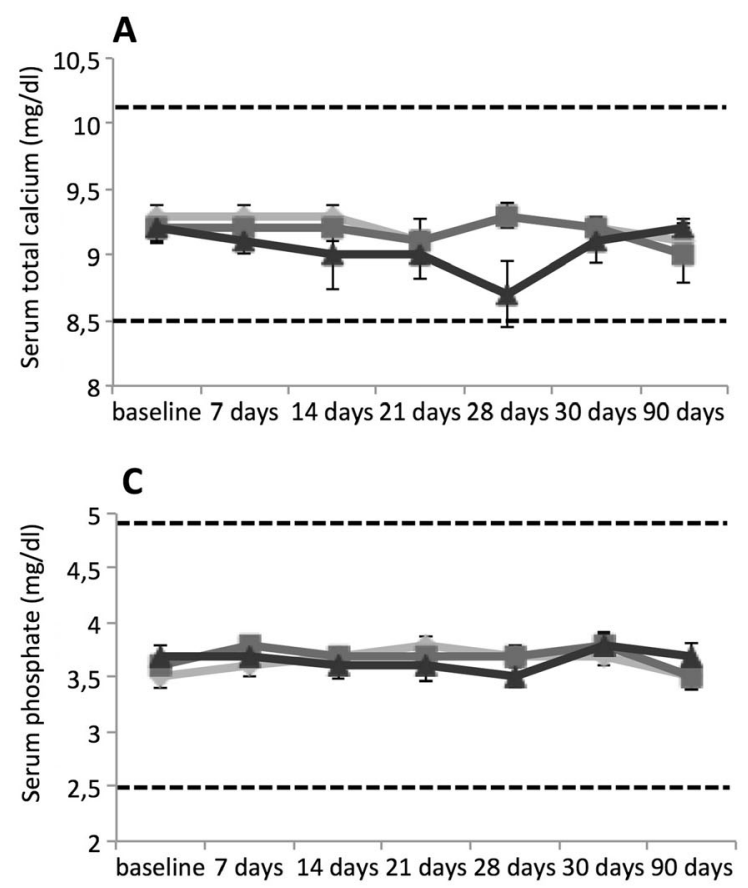

Fig. 2 Time profile of the values of serum calcium (mg/dl) (panel a), ionized calcium $(\mathrm{mg} / \mathrm{dl})$ (panel b), phosphate $(\mathrm{mg} / \mathrm{dl})$ (panel $\mathbf{c})$, and creatinine $(\mathrm{mg} / \mathrm{dl})$ (panel d) under different dose regimens of calcidiol $p=0.47, p=0.40$, and $p=0.43$ versus baseline for dosage 1,2 , and 3 , respectively), PTH significantly decreased over the 90 days (final versus baseline serum PTH: $p<0.0001$, $p<0.0001$, and $p=0.0005$ for dosage 1,2 , and 3, respectively), (Fig. 4a, b). Regarding VDBP (Supplementary Table 1, Fig. 4c), ANOVA for repeated measures showed a significant steady increase during the first 4 weeks of treatment ( $F$ value $=13.25$, Prob $>F<0.0001)$ (Fig. 4c).

Urinary parameters have been evaluated for safety issues. ANOVA for repeated measures confirmed no differences between treatments despite significant fluctuation during the study
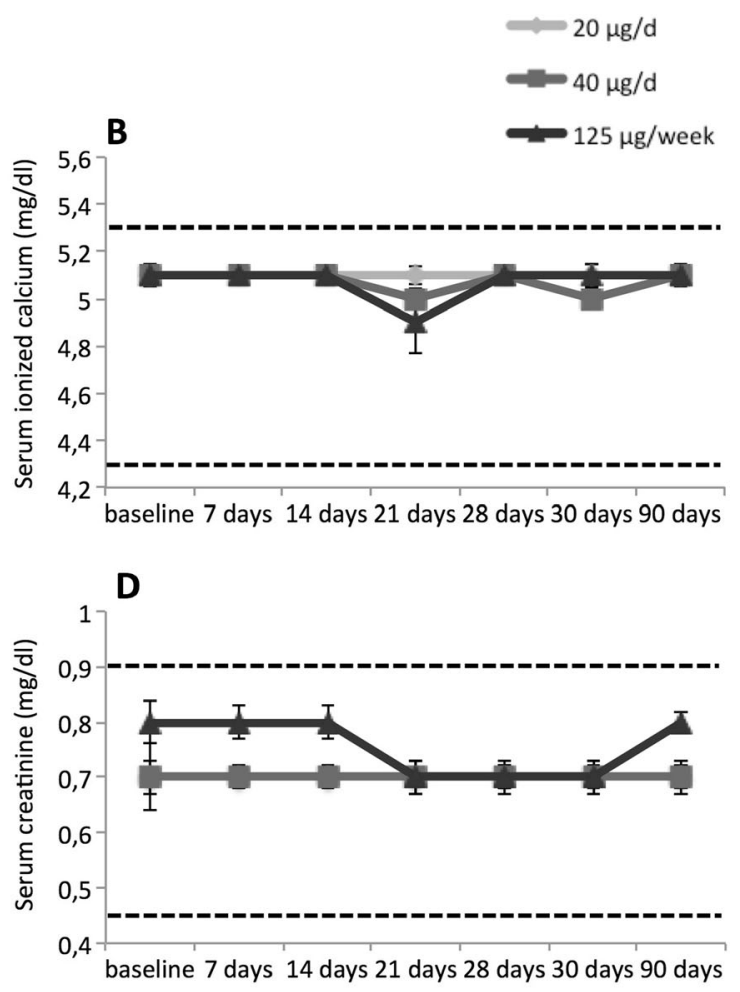

at various time points (mean $\pm \mathrm{SE}$ ); normal range is indicated between the dotted lines 


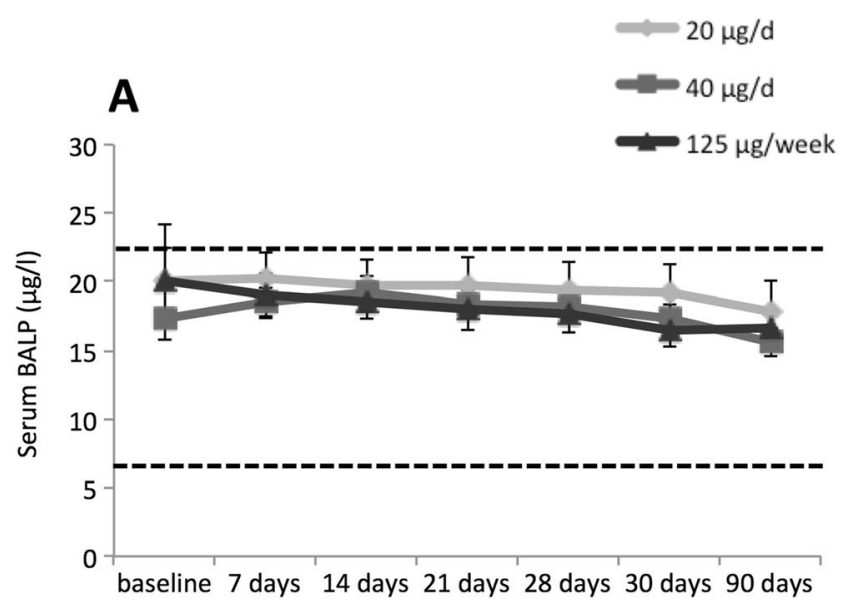

B

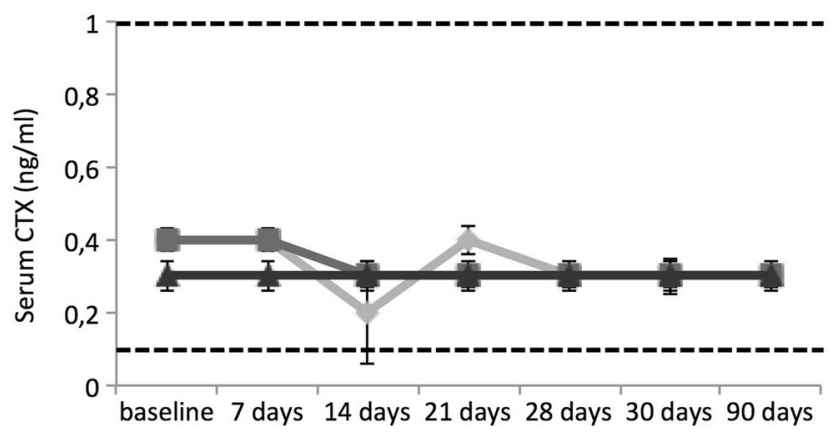

Fig. 3 Time profile of bone turnover markers [serum BALP $(\mu \mathrm{g} / \mathrm{l})(\mathrm{panel}$ a) and CTX (ng/ml) (panel b) under different dose regimens of calcidiol at various time points (mean $\pm \mathrm{SE}$ ); normal range is indicated between the dotted lines

for 24-h urinary calcium $(F$ value $=8.88$, Prob $>F<0.0001)$ (Supplementary Table 1) (Fig. 5). Although a steady increase in urinary calcium was observed during the treatment with the three dosage regimens, there was no evidence of hypercalciuria (i.e., calcium $>300 \mathrm{mg} / 24 \mathrm{~h}$ ). Indeed, urinary calcium plateaued between 30 and 90 days of treatment. Twenty-four-hour urinary phosphate, 24-h urinary creatinine, and urinary DPD did not differ between the different dose regimens (Supplementary Table 1).

Other biochemical parameters have been evaluated both for efficacy and safety survey of patient status. No relevant changes were observed for serum alkaline phosphatase, albumin, total proteins, ASAT, ALAT, GGT, $\mathrm{Na}, \mathrm{Cl}$, and $\mathrm{K}$ (data not shown).

Throughout the study, only four events have been detected, one per patient: three at center 1 (patient no. 20, dosage $40 \mu \mathrm{g}$ / day; patient no. 30 , dosage $20 \mu \mathrm{g} /$ day; patient no. 33 , dosage $125 \mu \mathrm{g} /$ day, and patient no. 34, dosage $125 \mu \mathrm{g} /$ day) and one at center 2 (patient no. 41, dosage $125 \mu \mathrm{g} /$ day). The three patients at center 1 reported a flu episode, while the patient at center 2 was found to be hypercalcemic in one occasion; this episode was considered "possibly" related to the treatment. All other events were not considered to be drug-related.

\section{Discussion}

The ADDI-D study extends previous observations on the efficacy of calcidiol when employed in vitamin D supplementation for vitamin $\mathrm{D}$ inadequacy in postmenopausal women with mean serum 25(OH)D levels below $20 \mathrm{ng} / \mathrm{ml}$ [15-17]. Moreover, for the first time, the effects of three different calcidiol regimens on core parameters of bone and mineral homeostasis in postmenopausal women with vitamin D inadequacy (i.e., serum $25(\mathrm{OH}) \mathrm{D}$ levels less than $30 \mathrm{ng} / \mathrm{ml}$ ) have been assessed. The results confirm calcidiol's prompt efficacy in correcting vitamin D status and underline its safety, at least in the short/medium term, also in regard to some non-classical, unwanted adverse events (e.g., alterations in bone turnover markers or increased fall rate) observed during supplementation with native vitamin D [11, 21, 22, 25].

Calcidiol, which is also the circulating form of vitamin $\mathrm{D}$ as well as the best marker of vitamin D status, has been marketed in Europe for vitamin D supplementation in several conditions $[13,14]$. Osteomalacia, the mineralization defect due to vitamin $\mathrm{D}$ deficiency, is its main therapeutic indication in adults. Especially in older individuals, this condition can coexist with an alteration of bone microarchitecture (namely osteoporosis). Calcidiol significantly decreases the osteoid volume and surface and greatly increases the front of calcification, normalizing biological parameters (serum calcium, phosphorus, AP) more efficiently than other vitamin D metabolites [13, 14].

When administering $25(\mathrm{OH}) \mathrm{D}$, this metabolite enters the circulation and hence bypasses liver metabolism. This, together with peculiar chemical characteristics of calcidiol (greater polarity, unusual for a steroidal compound) and its consequent pharmacokinetic properties, make this drug preferable when a rapid replenishment of $25(\mathrm{OH}) \mathrm{D}$ reservoir and/or additional potency for attaining desired amounts of $25(\mathrm{OH}) \mathrm{D}$ are required.

These peculiar properties have made calcidiol widely used as vitamin D supplement, as demonstrated by the analysis of regional administrative pharmaceutical databases [34].

In this study, calcidiol has been administered at three different regimens: two daily treatments of 20 and $40 \mu \mathrm{g}$, respectively, and a weekly treatment of $125 \mu \mathrm{g}$, similar to the calculated cumulative dose of the lower daily dosage. In all the three groups, serum $25(\mathrm{OH}) \mathrm{D}$ values significantly and promptly rose above the $20 \mathrm{ng} / \mathrm{ml}$ threshold so that the majority of subjects were vitamin D repleted after just 14 days of treatment. This can be exploited particularly when vitamin D status has to be optimized in a short interval of time, for example when antifracture therapy has to be undertaken in subjects at high risk for fracture (e.g., after a major fragility fracture or when commencing glucocorticoid therapy). The rapidity in correcting profound vitamin D deficiency with overt or insidious osteomalacia makes calcidiol a good alternative to the mega doses of parental vitamin $\mathrm{D}_{3}$, recently linked to increased falls and fractures [21,22], since the non- 

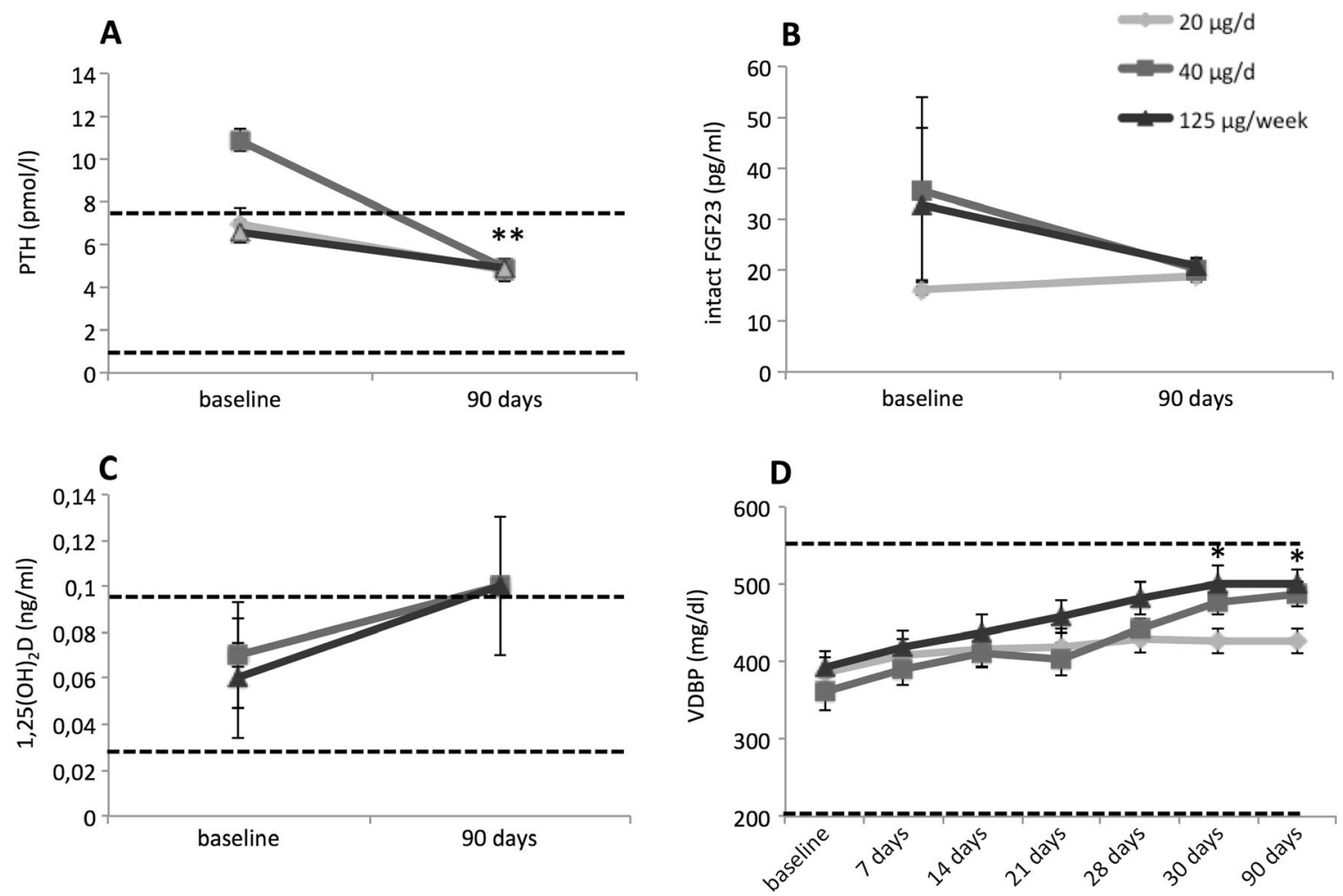

Fig. 4 Time profile of serum PTH (pmol/l) (panel a), intact FGF23 (pg/ $\mathrm{ml}$ ) (panel b), 1,25(OH) $)_{2} \mathrm{D}(\mathrm{ng} / \mathrm{ml})$ (panel $\left.\mathbf{c}\right)$, and VDBP (mg/dl) (panel d), and to different dose regimens of calcidiol at various time points

(mean $\pm \mathrm{SE}$ ); normal range is indicated between the dotted lines $\left({ }^{*} p<0.05\right.$ and ${ }^{*} p p<0.001$ versus baseline for all treatment groups)

physiological, abnormal higher peaks in the concentration of $25(\mathrm{OH}) \mathrm{D}$ are avoided. Because calcidiol is more powerful in attaining the desired serum $25(\mathrm{OH}) \mathrm{D}$ level and due to its smaller volume of distribution, it can be proposed as a better, active vitamin D precursor for obese individuals, in whom massive doses of cholecalciferol must be employed to reach the threshold of $30 \mathrm{ng} / \mathrm{ml}[14,35]$.

The baseline vitamin D status has a major influence on the percentual increase in serum $25(\mathrm{OH}) \mathrm{D}$ during cholecalciferol supplementation [33]. This does not seem to be true also for

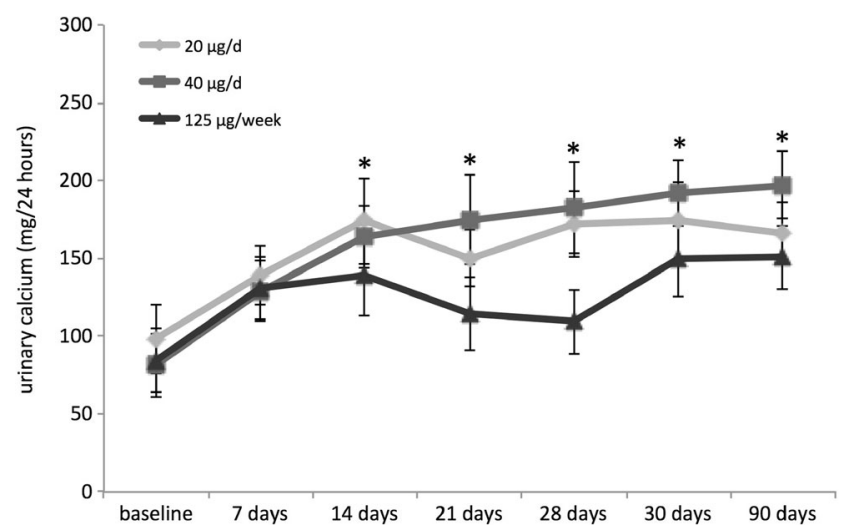

Fig. 5 Time profile of urinary calcium $(\mathrm{mg} / 24 \mathrm{~h})$ under different dose regimens of calcidiol at various time points (mean $\pm \mathrm{SE})\left({ }^{*} p<0.05\right.$ versus baseline for all treatment groups)

calcidiol, since, as demonstrated in the ADDI-D study, the increase in vitamin D levels obtained by calcidiol administration does not depend on initial vitamin $\mathrm{D}$ status. Indeed, the percentual gain in serum $25(\mathrm{OH}) \mathrm{D}$ levels comparable for women with baseline $25(\mathrm{OH}) \mathrm{D}$ less than $20 \mathrm{ng} / \mathrm{ml}$ and women with 25(OH)D comprised between 20 and $30 \mathrm{ng} / \mathrm{ml}$. Nonetheless, this observation requires further studies.

The similarity of efficacy of the daily and weekly dose regimens (i.e., $20 \mu \mathrm{g} /$ day and $125 \mu \mathrm{g} /$ week, respectively) in terms of attaining sufficient levels of $25(\mathrm{OH}) \mathrm{D}$ shown in this study confirm previous findings [15], indicating that administering calcidiol every day or administering an equal $(140 \mu \mathrm{g})$ [15] or similar $(125 \mu \mathrm{g})$ amount once a week or monthly [27] results in equal effectiveness with respect to attaining desired $25(\mathrm{OH}) \mathrm{D}$ levels. The efficacy of the lower dose regimens also demonstrates that there is no need to further increase the dosage in non-obese subjects to correct vitamin D status for optimizing mineral homeostasis. Nonetheless, the pharmacokinetic profile of the compound shows the attainment of a plateau of serum $25(\mathrm{OH}) \mathrm{D}$ levels in the long interval between 30 and 90 days of treatment, which is well below the upper limit of classical toxicity (i.e., hypercalciuria and hypercalcemia), even when administered at higher dose (40 $\mu \mathrm{g} /$ day). Nonetheless, given the increasing evidence of non-classical toxic effects (i.e., increased fall rate) for attained levels of serum 25(OH)D above $50 \mathrm{ng} / \mathrm{ml}[11,25]$, the higher dosages 
of calcidiol (i.e., $40 \mu \mathrm{g} /$ day) should be possibly avoided, particularly in frail individuals at high risk of falling and related consequences [36].

The results of the ADDI-D study suggest a good safety and manageability of this compound at lower dosages in clinical practice, without the need of close monitoring serum $25(\mathrm{OH}) \mathrm{D}$ in the short-medium term. Indeed, levels of VDBP increased steadily within the first 30 days, before the plateau in $25(\mathrm{OH}) \mathrm{D}$ concentrations during daily administration of $40 \mu \mathrm{g}$ and weekly administration of $125 \mu \mathrm{g}$. This may represent a buffering of the homeostatic vitamin D system itself to avoid dangerous increase in biologically active 25(OH)D.

In addition, a good predictability of achieved serum $25(\mathrm{OH}) \mathrm{D}$ levels has been observed, with increases by twofold though the administration of double doses of daily calcidiol.

Calcidiol has proven to be safe when administered at daily, weekly, monthly, or every other week [27] dose regimens. It is commonly used in clinical practice, without risk of vitamin D intoxication (i.e., hypercalciuria and hypercalcemia). Indeed, the attained $25(\mathrm{OH})$ levels are far below what is considered as the upper limit of normal values (i.e., $100 \mathrm{ng} / \mathrm{ml}$ ) as indicated by most laboratories in order to avoid the vitamin D-related classic toxic effects, namely hypercalciuria and hypercalcemia. Total and ionized calcium levels were stable up to 90 days of treatment. Moreover, serum phosphate and creatinine remained within the normal range, along with urinary markers and routine biochemical tests, and no difference was observed between different dosages, beside expected physiological fluctuations within the study period.

Regarding safety issues, this study for the first time has also assessed the effect of calcidiol on several additional markers of mineral metabolism.

The increase of markers of bone turnover has been suggested as possible mechanisms to explain unwanted nonclassic side effect of cholecalciferol [23, 24]. In this study, no increase of markers of bone turnover (such as serum BALP, CTX, and urinary DPD) was observed for any of the treatments with calcidiol within the whole interval of administration. Furthermore, in a previous study utilizing a monthly dose of $500 \mu \mathrm{g}$ calcidiol, a decrease of bone alkaline phosphatase was even observed [27].

As expected, a decrease of serum PTH levels as well as an increase of 25(OH)D concentration was observed. Notably, however, the different dosages were equally effective in controlling secondary hyperparathyroidism. Alterations of FGF23, phosphate metabolism, and $1,25(\mathrm{OH})_{2} \mathrm{D}$ have been indicated as possible mediators of non-classic toxic effects of cholecalciferol and/or possibly counteracting the effects of vitamin D [37, 38]. No differences in serum intact FGF23, phosphate, or $1,25(\mathrm{OH})_{2} \mathrm{D}$ concentrations were observed during daily or weekly calcidiol administration, further underlining the safety of this compound regarding potential, non-classic unwanted events.
Overall, the results of this study confirm the efficacy and safety of calcidiol, the direct precursor of calcitriol, when used, at least in the short/medium term, to treat vitamin D inadequacy or deficiency in postmenopausal women.

Given the growing recent evidence of increased number of falls for higher dosages of cholecalciferol leading to serum 25(OH)D above $50-60 \mathrm{ng} / \mathrm{ml}[11,25]$, caution has to be used before prescribing higher dosages of calcidiol (i.e., $40 \mu \mathrm{g} /$ day), particularly in subjects at high risk of falling, even if an increased risk of falling has not still been demonstrated for calcidiol supplementation. Indeed, no data on falls are available during calcidiol supplementation, while a better muscular performance has been demonstrated [16, 39]. We acknowledge that not having included fall assessment in the safety analysis is a limitation of our study. In this respect, further mid- and long-term studies are necessary in this field, having falls as primary outcome, particularly in at-high-risk individuals.

\section{Conclusions}

The study hereby presented demonstrates, for the first time, the efficacy of calcidiol as well as its safety on multiple parameters related to mineral and bone metabolism in the shortmedium term.

More studies are needed to further assess the calcidiol pharmacokinetics properties in the long term, along with unique properties of the compound that have not yet been fully recognized, such as musculoskeletal effects. Indeed, some randomized controlled trials have demonstrated increased muscle performance in postmenopausal women supplemented with calcidiol at usual doses with respect to cholecalciferol [16, 39], although the risk of falling during calcidiol supplementation has not been assessed yet as a primary outcome. These properties make calcidiol a good alternative to cholecalciferol in the treatment of the widespread vitamin D deficiency and related musculoskeletal consequences (osteomalacia, falls, and fractures), and even the supplement of choice when specific conditions hamper the efficacy of parental vitamin D.

Acknowledgments This work was supported though a dedicated grant from Bruno Farmaceutici (to Maria Luisa Brandi and Salvatore Minisola). We are indebted to Guido Fedele for the statistical analyses of the data.

\section{Compliance with ethical standards}

Conflict of interest Luisella Cianferotti, Piergianni Biondi, Caterina Fossi, Francesco Franceschelli, Francesca Giusti, Gigliola Leoncini, and Jessica Pepe declare that they have no conflict of interest.

Salvatore Minisola served as speaker for Abiogen, Amgen, Bruno Farmaceutici, Diasorin, Eli Lilly, Italfarmaco, Fujii, and Merck Sharp \& Dohme, Takeda. He served in advisory board of Amgen, Eli Lilly, and 
Merck Sharp \& Dohme and received paid consultancy from Bruno Farmaceutici.

Heike A. Bischoff-Ferrari contributed as invited speaker and on advisory boards for Roche, Pfizer, Sanofi, DSM Nutritional Products, Nestlé, and WILD. She received investigator initiated and independent funding from DSM Nutritional Products, Roche Diagnostics, Pfizer, and Nestlé.

Maria Luisa Brandi has received consultancy fees and grant support from Alexion, Abiogen, Amgen, Eli Lilly, and Shire.

\section{References}

1. Rizzoli R, Boonen S, Brandi ML, Bruyère $\mathrm{O}$, Cooper C, Kanis JA, Kaufman JM, Ringe JD, Weryha G, Reginster JY (2013) Vitamin D supplementation in elderly or postmenopausal women: a 2013 update of the 2008 recommendations from the European Society for Clinical and Economic Aspects of Osteoporosis and Osteoarthritis (ESCEO). Curr Med Res Opin 29:305-313

2. Rizzoli R, Stevenson JC, Bauer JM, van Loon LJ, Walrand S, Kanis JA, Cooper C, Brandi ML, Diez-Perez A, Reginster JY, Task Force ESCEO (2014) The role of dietary protein and vitamin D in maintaining musculoskeletal health in postmenopausal women: a consensus statement from the European Society for Clinical and Economic Aspects of Osteoporosis and Osteoarthritis (ESCEO). Maturitas 79:122-132

3. Herrmann M, Farrell CL, Pusceddu I, Fabregat-Cabello N, Cavalier E (2017) Assessment of vitamin D status - a changing landscape. Clin Chem Lab Med 55:3-26

4. Chapuy MC, Preziosi P, Maamer M, Arnaud S, Galan P, Hercberg S, Meunier PJ (1997) Prevalence of vitamin D insufficiency in an adult normal population. Osteoporos Int 7:439-443

5. Pepe J, Romagnoli E, Nofroni I, Pacitti MT, De Geronimo S, Letizia C, Tonnarini G, Scarpiello A, D'Erasmo E, Minisola S (2005) Vitamin D status as the major factor determining the circulating levels of parathyroid hormone: a study in normal subjects. Osteoporos Int 16:805-812

6. Romagnoli E, Pepe J, Piemonte S, Cipriani C, Minisola S (2013) Management of endocrine disease: value and limitations of assessing vitamin D nutritional status and advised levels of vitamin D supplementation. Eur J Endocrinol 169:R59-R69

7. Souberbielle JC, Brazier F, Piketty ML, Cormier C, Minisola S, Cavalier E (2017) How the reference values for serum parathyroid hormone concentration are (or should be) established? J Endocrinol Investig 40:241-256

8. Bischoff-Ferrari HA, Dietrich T, Orav EJ, Dawson-Hughes B (2004) Positive association between 25-hydroxy vitamin D levels and bone mineral density: a population-based study of younger and older adults. Am J Med 116:634-639

9. Bischoff-Ferrari HA, Willett WC, Orav EJ, Orav EJ, Lips P, Meunier PJ, Lyons RA, Flicker L, Wark J, Jackson RD, Cauley JA, Meyer HE, Pfeifer M, Sanders KM, Stähelin HB, Theiler R, Dawson-Hughes B (2012) A pooled analysis of vitamin D dose requirements for fracture prevention. N Engl J Med 367:40-49

10. Carmeliet G, Dermauw V, Bouillon R (2015) Vitamin D signaling in calcium and bone homeostasis: a delicate balance. Best Pract Res Clin Endocrinol Metab 29:621-631

11. Bischoff-Ferrari HA, Dawson-Hughes B, Orav EJ, Staehelin HB, Meyer OW, Theiler R, Dick W, Willett WC, Egli A (2016) Monthly high-dose vitamin $\mathrm{D}$ treatment for the prevention of functional decline: a randomized clinical trial. JAMA Intern Med 176:175-183

12. Holick MF, Binkley NC, Bischoff-Ferrari HA, Gordon CM, Hanley DA, Heaney RP, Murad MH, Weaver CM (2012) Guidelines for preventing and treating vitamin D deficiency and insufficiency revisited. J Clin Endocrinol Metab 97:1153-1158
13. Brandi ML, Minisola S (2013) Calcidiol [25(OH)D3]: from diagnostic marker to therapeutical agent. Curr Med Res Opin 29:1565-1572

14. Cianferotti L, Cricelli C, Kanis JA, Nuti R, Reginster JY, Ringe JD, Rizzoli R, Brandi ML (2015) The clinical use of vitamin D metabolites and their potential developments: a position statement from the European Society for Clinical and Economic Aspects of Osteoporosis and Osteoarthritis (ESCEO) and the International Osteoporosis Foundation (IOF). Endocrine 50:12-26

15. Jetter A, Egli A, Dawson-Hughes B, Staehelin HB, Stoeklin E, Goessl R, Henschkowski J, Bischoff-Ferrari HA (2014) Pharmacokinetics of oral vitamin $\mathrm{D}(3)$ and calcifediol. Bone 59:14-19

16. Bischoff-Ferrari HA, Dawson-Hughes B, Stocklin E, Sidelnikov E, Willett WC, Edel JO, Stähelin HB, Wolfram S, Jetter A, Schwager J, Henschkowsi J, von Eckardstein A, Egli A (2012) Oral supplementation with $25(\mathrm{OH}) \mathrm{D} 3$ versus vitamin D3: effects on $25(\mathrm{OH}) \mathrm{D}$ levels, lower extremity function, blood pressure, and markers of innate immunity. J Bone Miner Res 27:160-169

17. Cashman KD, Seamans KM, Lucey AJ, Stöcklin E, Weber P, Kiely M, Hill TR (2012) Relative effectiveness of oral 25hydroxyvitamin D3 and vitamin D3 in raising wintertime serum 25-hydroxyvitamin D in older adults. Am J Clin Nutr 95: $1350-1356$

18. Cipriani C, Romagnoli E, Pepe J, Russo S, Carlucci L, Piemonte S, Nieddu L, McMahon DJ, Singh R, Minisola S (2013) Long-term bioavailability after a single oral or intramuscular administration of 600,000 IU of ergocalciferol or cholecalciferol: implications for treatment and prophylaxis. J Clin Endocrinol Metab 98:2709-2715

19. Vieth R (1999) Vitamin D supplementation, 25-hydroxyvitamin D concentrations, and safety. Am J Clin Nutr 69:842-856

20. Bischoff-Ferrari HA, Shao A, Dawson-Hughes B, Hathcock J, Giovannucci E, Willett WC (2009) Benefit-risk assessment of vitamin D supplementation. Osteoporos Int 21:1121-1132

21. Smith H, Anderson F, Raphael H, Maslin P, Crozier S, Cooper C (2007) Effect of annual intramuscular vitamin D on fracture risk in elderly men and women - a population-based, randomized, double-blind, placebo-controlled trial. Rheumatology (Oxford) 46:1852-1857

22. Sanders KM, Stuart AL, Williamson EJ, Simpson JA, Kotowicz MA, Young D, Nicholson GC (2010) Annual high-dose oral vitamin D and falls and fractures in older women: a randomized controlled trial. JAMA 303:1815-1822

23. Rossini M, Gatti D, Viapiana O, Fracassi E, Idolazzi L, Zanoni S, Adami S (2012) Short-term effects on bone turnover markers of a single high dose of oral vitamin $\mathrm{D}_{3}$. J Clin Endocrinol Metab 97:E622-E626

24. Rossini M, Adami S, Viapiana O, Fracassi E, Idolazzi L, Povino MR, Gatti D (2012) Dose-dependent short-term effects of single high doses of oral vitamin $\mathrm{D}(3)$ on bone turnover markers. Calcif Tissue Int 91:365-369

25. Smith LM, Gallagher JC, Suiter C (2017) Medium doses of daily vitamin D decrease falls and higher doses of daily vitamin D3 increase falls: a randomized clinical trial. J Steroid Biochem Mol Biol. doi:10.1016/j.jsbmb.2017.03.015

26. Haddad JG Jr, Rojanasathit S (1976) Acute administration of 25-hydroxycholecalciferol in man. J Clin Endocrinol Metab 42:284-290

27. Russo S, Carlucci L, Cipriani C, Ragno A, Piemonte S, Fiacco RD, Pepe J, Fassino V, Arima S, Romagnoli E, Minisola S (2011) Metabolic changes following $500 \mu \mathrm{g}$ monthly administration of calcidiol: a study in normal females. Calcif Tissue Int 89:252-257

28. Lawson DE, Sedrani SH, Douglas J (1986) Interrelationships in rats of tissue pools of cholecalciferol and 25-hydroxycholecalciferol formed in u.v. light. Biochemist J233:535-540 
29. Chun RF, Peercy BE, Orwoll ES, Nielson CM, Adams JS, Hewison M (2014) Vitamin D and DBP: the free hormone hypothesis revisited. J Steroid Biochem Mol Biol 144 Pt A:132-137

30. Heaney RP, Armas LA, Shary JR, Bell NH, Binkley N, Hollis BW (2008) 25-Hydroxylation of vitamin D3: relation to circulating vitamin D3 under various input conditions. Am J Clin Nutr 87:1738-1742

31. Davies M, Mawer EB, Krawitt EL (1980) Comparative absorption of vitamin D3 and 25-hydroxyvitamin D3 in intestinal disease. Gut 21:287-292

32. Michaud J, Naud J, Ouimet D, Demers C, Petit J-L, Leblond FA, Bonnardeaux A, Gascon-Barré M, Michette V (2010) Reduced hepatic synthesis of calcidiol in uremia. J Am Soc Nephrol 21: 1488-1497

33. Gonnelli S, Rossi S, Montomoli M, Caffarelli C, Cuda C, Lazzeri G, Giacchi M, Nuti R (2009) Accuracy of different reduced versions of a validated food-frequency questionnaire in Italian men and women. Calcif Tissue Int 85:221-227

34. Cianferotti L, Parri S, Gronchi G, Rizzuti C, Fossi C, Black DM, Brandi ML (2015) Changing patterns of prescription in vitamin D supplementation in adults: analysis of a regional dataset. Osteoporos Int 26:2695-2702

35. Gallagher JC, Sai A, Templin T 2nd, Smith L (2012) Dose response to vitamin D supplementation in postmenopausal women: a randomized trial. Ann Intern Med 156:425-437

36. Fuleihan G-H, Bouillon R, Clarke B, Chakhtoura M, Cooper C, McClung M, Singh RJ (2015) Serum 25-hydroxyvitamin D levels: variability, knowledge gaps, and the concept of a desirable range. J Bone Miner Res 30:1119-1133

37. Blau JE, Collins MT (2015) The PTH-vitamin D-FGF23 axis. Rev Endocr Metab Disord 16:165-174

38. Han X, Quarles LD (2016) Multiple faces of fibroblast growth factor-23. Curr Opin Nephrol Hypertens 25:333-342

39. Meyer O, Dawson-Hughes B, Sidelnikov E, Egli A, Grob D, Staehelin HB, Theiler G, Kressig RW, Simmen HP, Theiler R, Bischoff-Ferrari HA (2015) Calcifediol versus vitamin D3 effects on gait speed and trunk sway in young postmenopausal women: a double-blind randomized controlled trial. Osteoporos Int 26:373-381 